\title{
COMPARISON OF EXTRAPLEURAL ANTEROLATERAL DECOMPRESSION AND TRANSTHORACIC ANTERIOR DECOMPRESSION FOR TUBERCULOSIS OF THE DORSAL SPINE
}

\author{
Navin KumarKarn, Ranjeev Jha, PrakashSitoula, MahipalSingh, Anil Kumar Jain
}

\begin{abstract}
Background: Spinal tuberculosis (TB) comprises 50\% of all skeletal tuberculosis and it affects body of the vertebra in about $98 \%$ of the cases, hence surgical decompression when needed should be anterior.There are a number of studies describing transthoracic approach but very few describing extrapleural anterolateral approach and none were comparative trial. Therefore, the present study was conducted to compare extrapleural anterolateral decompression and transthoracic anterior decompression for tuberculosis of dorsal spine.
\end{abstract}

Aims and Objectives: To compare the duration of surgery, amount of blood loss, neurological recovery and complication rate.

Design: Prospective Randomised controlled Trial

Setting: The study was performed in Department of Orthopedics, NMCH,Biratnagar, Nepal

Material and methods: The patients with tuberculosis of dorsal spine those required surgical decompression were randomly allocated into two groups. For the first group we performed extrapleural anterolateral decompression and for the second group we performed transthoracic anterior decompression

We excluded patients with ischemic heart disease, end stage renal disease, immunocompromised stage. We did follow up for one year with comparing outcome in terms of duration of surgery, amount of blood loss neurological recovery and complication rate.

Results: 60 patients were left after exclusion. We found duration of surgery, amount of blood loss were significantly higher in transthoracic anterior decompression group. There was single case of wound infection (3.3\%)in the transthoracic anterior decompression group. 3 cases of transthoracic anterior decompression had to convert into anterolateral decompression because of adhesion of pleura to lung. There was no significant difference in neurological recovery and development of kyphotic deformity.

\section{Conclusion}

We found anterolateral decompression did better than transthoracic anterior decompression in terms of duration of surgery, amount of blood loss, postoperative morbidity but similar neurological recovery rate.

Key words:Anterolateral, transthoracic decompression, tuberculosis dorsal spine 


\section{Introduction}

Spinal tuberculosis (TB) comprises $50 \%$ of all skeletal tuberculosis and it affects body of the vertebra in about $98 \%$ of the cases, hence surgical decompression when needed should be anterior ${ }^{1}$. Laminectomy is advocated with posterior complex disease and intraspinous tubercular granuloma presenting as spinal tumor syndrome ${ }^{2}$.The common indications for surgical decompression are detoriation of neurological deficit during conservative treatment, the development of neurological defecit while patients are on antitubercular therapy, no neurological improvement on antitubercular therapy and complete paraplegia. In the dorsal spine, anterior decompression can be performed through either an extrapleural anterolateral approach or a transthoracic anterior approach. The transthoracic approach has been described by various authors ${ }^{3-5}$ and few studies are on extrapleural approach ${ }^{6,7}$. All the studies have dealt on the surgical approaches but none have compared the two surgical approaches. Therefore, the present study was conducted to compare extrapleural anterolateral decompression and transthoracic anterior decompression for tuberculosis of dorsal.

\section{Material and methods}

In 2012,64 patients with tuberculosis of dorsal spine that needed surgical intervention and giving informed consent to participate in trial were included in the study. The patients with ischemic heart disease, end stage renal disease, immunocompromised state were excluded from the study. This left 60 patients available for the study.

The patients were randomly selected for anterior decompression by extrapleural anterolateral approach and by transthoracic anterior approach. There were 30 patients in each group. All patients gave informed consent to participate in the study. The American Society of Anesthesiologist (ASA) scale was used to classify any co - morbidities. In the extrapleural approach 12 patients were classified as ASA grade 2 and 18 patients as ASA grade 3 , while in transpleural approach 10 patients were classified as ASA 2 and 20 patients as ASA 3. All the patients were given antitubercular therapy according to standard protocol. All patientsreceived general anesthesia. For extrapleural anterolateral approach the patient to be taken for decompression on left side was placed in the right lateral position. A Tshaped incision started in the midline for about 14 to $15 \mathrm{~cm}$ with the apex of the kyphos as its centre.(Fig 1)

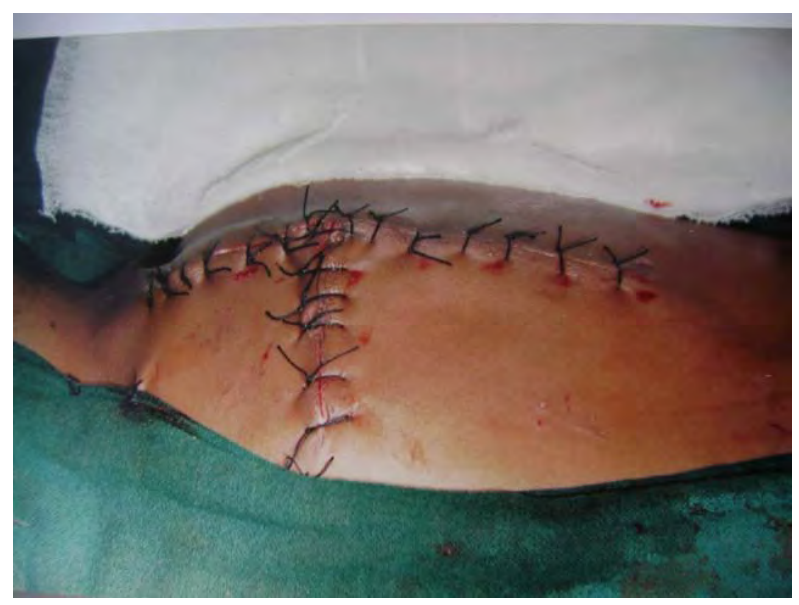

The transverse cut was made to about $8 \mathrm{~cm}$ from the midline at the apex of kyphus on the left side. The skin, subcutaneous tissue and the deep fascia were incised in the same line. This created a full thickness fasciocutaneous flap. The trapezius, latissimus dorsi and periscapular muscles were divided in a $\mathrm{T}$ shaped manner.

The ribs to be removed were identified and marked. The periosteum of each rib was incised in the long axis of the rib and elevated. Since the intercostal muscles are attached obliquely to the ribs, the dissection was performed in the axilla between the muscle fibres and the rib. Thick periosteum in the adolescent, facilitates its removal. The rib was divided lateral to its angle, about $8 \mathrm{~cm}$ 
away from the tip of the transverse process using bone cutting forceps, and was freed to its head. The paraspinal muscles were divided transversly in the line of each rib. The cleavage was created between the transverse process and the head of the rib dividing costotransverse ligament. The transverse process was removed from its bed and rib including its head was detached.

After the removal of the middle rib, adjacent ribs were removed in a similar manner. The intercostals artery and the nerve, leading to intervertebral foramenwere ligated and divided 2 inches away from spinal foramina. The lowermost intercostals nerve was spared when four of the lower six ribs were removed. The lateral and anterior surface of vertebral body was exposed and a blunt spatula was inserted anterior to the vertebral body. Any loose bony sequestra, sequestrated disc tissue, pus and granulation tissue were removed. The vertebral body is breached at the junction of the pedicle and the transverse process and the bone was removed bit by bit until the lateral and anterior wall of the spinal canal is decompressed. The spinal cord was exposed for the whole length of three vertebra (i.e. $5 \mathrm{~cm} \times 1 \mathrm{~cm})$. Patency of the spinal canal was confirmed by inserting an infant feeding tube proximally and distally. A slot was made in the proximal and the distal healthy vertebral body in order to put bone graft. The kyphos was corrected manually by applying pressure at its apex. Posterior fixation with Hartshill was done in four cases. Two ribs of appropriate length were fitted into the gap which was created. When the pressure on the back was released, the graft tends to locked in position. The lungs were inflated to check that no inadvertent pleural tear had been made before wound closure.

The transthoracic anterior decompression was done according to standard technique as described in Campbell's Operative Orthopedics ${ }^{5}$ and the chest tube was put in all the cases. (Fig No-2)

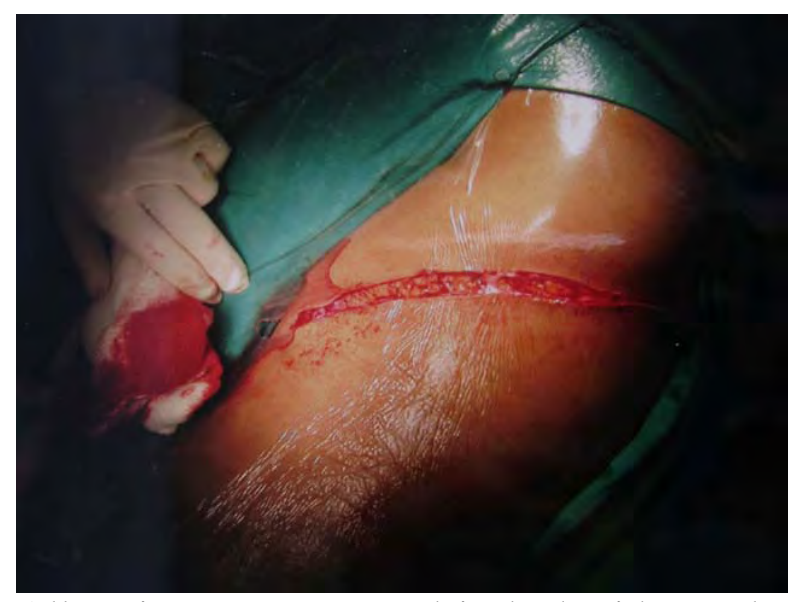

All patients were nursed in bed with regular turning at two hourly interval. Parental antibiotics to cover both gram positive and gram negative organisms were given for 48 hours after surgery. The chest tube was removed once the collection was less than 50 $\mathrm{ml}$ and noting the lung expansion in $\mathrm{X}$ ray chest.Post operatively X-ray dorsal spine was done to know the graft placement and decrease in the size of paravertebral shadow.

All the patients received uninterupted multidrug anti-tubercular therapy for 12 months. Removal of the suture done at 2 weeks and patients follwed up at 6 weeks than 3 monthly for one year. The neurological recovery and kyphos angle was noted in every follow up. All the patients who could not show the neurological recovery at 6 weeks of surgery underwent myelography in order to see the possible block.

This study had ethical approval.

Statistical analysis The data were entered using Microsoft EXCEL version 8 (Microsoft Corporation, Redmond, Washington). The success of randomization was tested by comparing descriptive variables such as age, gender, hematological parameters, neurological deficeit etc. Any discrepancies were measured as the difference between the means in both groups. The significance of these differences was measured using parametric analysis of variance (ANOVA) or the non-parametric Kruskall-Wallis test 
derived from the Epi Info computer program (Environmental System Research Inc., New Delhi, India)

\section{Results}

Both groups were comparable in terms of age, gender, hematological parameters etc $(\mathrm{p}>0.05)$

\section{Table No.1 Patients Details(Testing Randomisation)}

\begin{tabular}{|c|c|c|c|}
\hline & ALD & $\mathrm{AD}$ & P-Value \\
\hline Age in years & 34.56 & 36.80 & 0.6385 \\
\hline $\begin{array}{c}\text { Gender } \\
\text { M:F }\end{array}$ & $14: 16$ & $16: 14$ & 0.7962 \\
\hline $\begin{array}{l}\text { Hematological } \\
\text { Parameters } \\
\text { Hemoglobin(gm } \\
\% \text { ) } \\
\text { Serum } \\
\text { Protein(mg\%) }\end{array}$ & $\begin{array}{l}11.42 \\
7.65\end{array}$ & $\begin{array}{l}11.79 \\
7.85\end{array}$ & $\begin{array}{l}0.565 \\
0.861\end{array}$ \\
\hline $\begin{array}{l}\text { Neurological } \\
\text { deficiet } \\
\text { Yes } \\
\text { No } \\
\end{array}$ & $\begin{array}{l}26 \\
4 \\
\end{array}$ & $\begin{array}{l}24 \\
6 \\
\end{array}$ & 0.615 \\
\hline $\begin{array}{l}\text { Level of } \\
\text { involvement } \\
\text { Upper dorsal } \\
\text { spine D1-D6 } \\
\text { Lower dorsal } \\
\text { spine } \\
\text { D6-D12 } \\
\end{array}$ & $\begin{array}{l}8 \\
22\end{array}$ & $\begin{array}{l}10 \\
20\end{array}$ & 0.641 \\
\hline $\begin{array}{l}\text { No of vertebra } \\
\text { involved } \\
\text { upto3 } \\
>3\end{array}$ & $\begin{array}{l}22 \\
8\end{array}$ & $\begin{array}{l}26 \\
4\end{array}$ & 0.6292 \\
\hline $\begin{array}{l}\text { Preoperative } \\
\text { Kyphosis }\end{array}$ & 38.6 & 36.2 & 0.765 \\
\hline $\begin{array}{l}\text { ASA+ grading } \\
1 \\
2 \\
3 \\
\end{array}$ & $\begin{array}{l}0 \\
12 \\
18\end{array}$ & $\begin{array}{l}0 \\
10 \\
20 \\
\end{array}$ & \\
\hline
\end{tabular}

+ASA, American Society of Anaesthesiologists
(Table1).3 cases of transthoracic anterior decompression had to convert into anterolateral decompression because of adhesion of pleura to lung.(Fig-3)

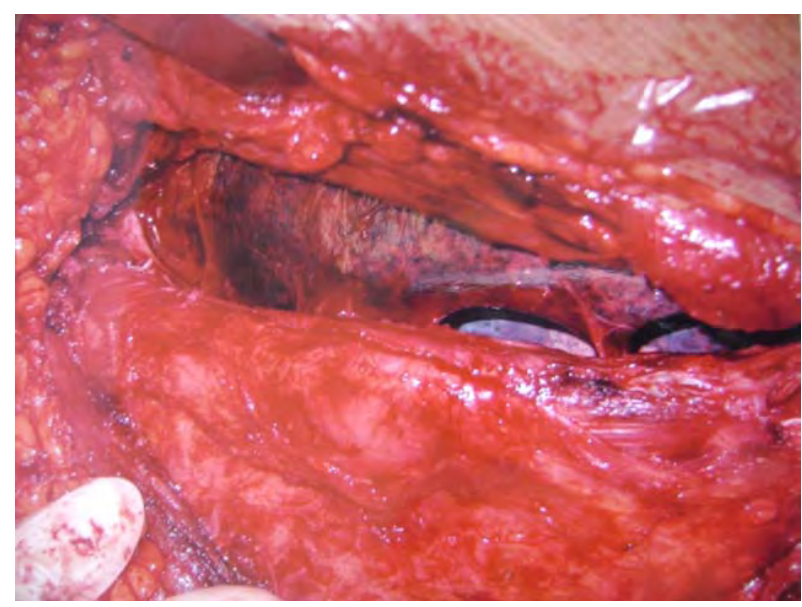

The outcome measurement in both the groups is shown in Table 2.

Table No-2 Showing comparison of the outcomes in the two groups

\begin{tabular}{|l|l|l|l|l|}
\hline & ALD & AD & $\begin{array}{l}\text { p- } \\
\text { value }\end{array}$ & $\begin{array}{l}\text { Krusk } \\
\text { all- } \\
\text { Wallis }\end{array}$ \\
\hline $\begin{array}{l}\text { Duration of } \\
\text { Surgery } \\
\text { without } \\
\text { instrumentat } \\
\text { ion (hours) }\end{array}$ & 2.17 & 3.02 & 0.001 & 0.001 \\
$\begin{array}{l}\text { Duration of } \\
\text { Surgery } \\
\text { with } \\
\text { instrumentat } \\
\text { ion (hours) }\end{array}$ & 3.67 & 4.81 & 0.001 & 0.001 \\
\hline $\begin{array}{l}\text { Blood loss } \\
\text { without } \\
\text { instrumentat } \\
\text { ion }\end{array}$ & 655.8 & 1039.9 & 0.014 & 0.010 \\
\hline $\begin{array}{l}\text { Blood loss } \\
\text { with } \\
\text { instrumentat } \\
\text { ion }\end{array}$ & 955.8 & 1239.9 & 0.014 & 0.010 \\
\hline $\begin{array}{l}\text { Wound } \\
\text { dehiscence }\end{array}$ & 0 & 1 & 0.06 & 0.066 \\
\hline $\begin{array}{l}\text { Neurologica } \\
\text { l recovery }\end{array}$ & 24 & 22 & 0.860 & 0.800 \\
\hline
\end{tabular}


Blood loss and duration of surgery were significantly higher in transthoracic group. 21 patients in extrapleural anterolateral group and 20 patients in transthoracic transpleural group showed neurological recovery within 6 weeks of the surgery. All the patients who could not show the neurological recovery at 6weeks of surgery underwent myelography which revealed no block. This indicated that an adequate surgical decompression had been achieved. 3 patients in extrapleural anterolateral group and 2 patients in transthoracic anterior group showed first sign of neurological recovery at 3 months. 2 patients in anterolateral group and 2 patients in transthoracic group did not show neurological recovery. At the end of one year there was no significant change in kyphosis. One patient in transthoracic group had wound dehiscence for which debridement was done followed by secondary suturing.

\section{Discussion}

In osteoarticular tuberculosis the areas of the bone which are infilterated with granulation tissue are ischaemic but not necrosed will recover and reconstitute under multidrug therapy only. Surgery, in addition to chemotherapy is essential for areas of necrosisthat must be assumed to harbour tubercular bacilli, and for complications such as paraparesis and spinal deformity. While performing surgical debridement, all pus, caseous material and sequestra should be removed. Removal of unaffected and viable bone is restricted to that which is required in order to provide adequate access to the infective focus and to decompress the spinal canal $^{1}$. By contrast radical surgery (the Hong Kong procedure) is defined as excision of bone until healthy bleeding cancellous bone with suitable surfaces for reception of bone graft is exposed. The marginal correction of the kyphus and healing of the lesion was reported by Upadhyay et $\mathrm{al}^{7}$ in a comparative series of either radical or debridement surgery in a total of 112 patients with a mean follow up of 15.3 years. Graft related complications such as displacement, breakage and late recurrence of a kyphus have been reported from $41 \%$ to $46.4 \%{ }^{8,9}$. When the graft spans two or more vertebral bodies, supplementary posterior instrumentation is recommended in order to prevent deterioration of the kyphosis $^{10}$.

Patients with spinal TB are anaemic, often with evidence of healing pulmonary TB, have paretic or paralysed intercostal muscles with compromised pulmonary function and have moderate to severe kyphosis. Thoracotomy in such cases is a procedure of some magnitude and should not be undertaken lightly even the place where adequate surgical facilities exist. It certainly should not be undertaken where surgical facilities are poor. In a series of 91 patients treated by thoracotomy seven died with respiratory failure ${ }^{11}$. In patients with coexistant pulmonary tuberculosis and compromised respiratory function, thoracotomy may aggravate the symptoms.

Surgical decompression is better tolerated in patients with TB of cervical spine and quadriplegia than those with TB of the dorsal spine with paraplegia. It seems that thoracotomy adds more morbidity to an already compromised pulmonary function, than does direct pressure on the cervical cord $^{11}$.

Adendorff et al ${ }^{3}$ have shown that mortality rate after thoracotomy was $6 \%$ when paraplegia is graded as moderate and 11\% when it is graded as severe. We did not encounterany mortality in one year .

Tuli $^{2}$,Dott $^{12}$, Capner ${ }^{13}$, and Seddon ${ }^{14}$ all describried a semicircular incision, concave medially, for decompression of the spinal cord. We modified incision to a T-shape to give adequate exposure for anterolateral decompression as described by Jain et $\mathrm{al}^{7}$ so that instrumentation became easier.

Anterolateral decompression is not free of problems. There is long learning curve and 
one may find difficulty in graft placement. It is however basically simple and safe; by not opening the pleural cavity, pulmonary complications are few. Even a debilitated patient can be operated upon with little postoperative morbidity.

\section{Conclusion}

The determining factors for a particular approach are preference, the technical skill of the surgeon, the availability of surgical and intensive care facilities and the pulmonary reserve of the patient.We found anterolateral decompression did better than transthoracic anterior decompression in terms of duration of surgery, amount of blood loss, postoperative morbidity but similar neurological recovery rate.

\section{Acknowledgement}

The authors thank paramedics and operating room staff in NMCTH for their help in completion of this study.

\section{References}

1. Jain AK Treatment of tuberculosis of the spine with neurological complication.Clinical Orthop 2002;398:75-84.

2. Tuli SM.Tuberculosis of the skeletal system Second ed. New Delhi:Jaypee Brothers Medical Publishers Ltd, 1997;217-301.

3. Adendorff $\mathbf{J} \mathbf{J}$, Boeke EJ, Lazarus C Tuberculosis of the spine ; Results of management of 300 patients. J R Coll Surg Edin 1987;32 : 152155.

4. Hodgson AR, Stock FE, Fang HSY, Ong GB Anterior spinal fusion: the operative approach and pathological findings in 412 patients with potts disease of the spine Br J Surg 1960;48:172-178.

5. Leventhal MRSpinal Anatomy and Surgical Approach : Campbell's Operative Orthopedics $10^{\text {th }}$ edn Vol-11 2003pp 1569-1596.

6. Jain AK, Agrawal A, Dhami IK, Agrawal PK, Singh S. Extrapleural anterolateral decompression in tuberculosis of the dorsal spine $J$ Bone Joint Surg 2004; 86-B 1027-1031.

7. Upadhaya SS, Saji MJ, Seff P, Hsu LC Surgical management of spinal tuberculosis in adults.Clin Orthop 1994;302:173-182.

8. Jenkin DHR, Hodgson AR, Yau ACM et al Stabilization of spine in the surgical treatment of severe spinal tuberculosis in children Clin Orthop 1975;110:69-80.

9. Rajasekaran S, Soundasapandian S Progression of kyphosis in tuberculosis of the spine treated by anterior arthrodesis $J$ Bone Joint Surg1989;71 A: 1314-1324.

10. Chen WJ, Chen CH, Shih CH Surgical treatment of tubercular spondylitis: 50 patients followed for 2-8 years Acta Orthop Scand 1995; 66:137-142.

11. Vidyasagar C, Srinivasa. H Management of tuberculosis of the spine with neurological complications . Ann.R.Coll.Surg Engl 1994;76:8084.

12. Dott NM Skeletal traction and anterior decompression in the management of Pott's paraplegia. Edinberg Med J 1949; 54:620-627.

13. Capener $\mathbf{N}$ The evaluation of lateral rhachotomy.J Bone Joint Surg 1954; 36-B :173-179.

14. Seddon HJ (1935) Pott's Paraplegia, prognosis and treatment.Br.J.Surg.22: 769-799.

Correspondence Address:Dr.Navin Kumar Karn Associate Professor Department of Orthopaedics Nobel Medical College \& Teaching Hospital, Biratnagar, Nepal E-mail: navinkarn@yahoo.comTel No: 00977-9852027814 